COMENTARIOS 


\section{EL ESTADO MEXICANO ACEPTA LA JURISDICCIÓN DE LA CORTE INTERAMERICANA DE DERECHOS HUMANOS}

\section{Susana NÚÑEZ PALACIOS}

RESUMEN: El 16 de diciembre de 1998 nuestro país aceptó la competencia contenciosa de la Corte Interamericana de Derechos Humanos, excluyendo la jurisdicción de la Corte en asuntos relativos al artículo 33 de la Constitución. De acuerdo con lo anterior, la autora analiza este acontecimiento, planteando principalmente dos cuestiones: por un lado, los elementos que pudieron influir para que nuestro país tomara esa decisión a casi veinte años de haberse adherido a la Convención Americana de Derechos Humanos. Y por otro, la reserva sobre el artículo 33 de la Constitución.
ABSTRACT: On December 16, 1998 our country accepted the contentious competence of the Inter-American Court of Human Rights, excluding matters related to article 33 of the Constitution from the Court's jurisdiction. Accordingly, the author analyses this event, establishing mainly two issues: on the one hand the elements that might have influenced the decision, 20 years after adhering to the American Convention on Human Rights; and on the other, the reservation form article 33 of the Constitution. 
SUMARIO: I. Introducción. II. Antecedentes. III. La Convención Americana sobre Derechos Humanos. IV. La Comisión y la Corte interamericanas de Derechos Humanos. V. La competencia contenciosa de la Corte Interamericana. VI. Contenido y alcance de la declaración hecha por el gobierno mexicano.

VII. Declaraciones interpretativas. VIII. Bibliografía.

\section{INTRODUCCIÓN}

El 16 de diciembre de 1998 el gobierno mexicano depositó en la Secretaría de la OEA, el instrumento en el cual acepta la competencia contenciosa de la Corte Interamericana de Derechos Humanos (CIDH). Tomando en cuenta que la propuesta de esta Declaración fue enviada al Senado mexicano el 10 de septiembre del mismo año, debemos reconocer que su aprobación se realizó en un corto plazo. ¿Responde esto a un cambio en la postura del gobierno mexicano hacia las instancias internacionales protectoras de los derechos humanos? Con anterioridad, diversas autoridades mexicanas habían justificado la no aceptación de la competencia de la CIDH argumentando que en México existen los mecanismos necesarios para reivindicar los derechos de la población; en otras ocasiones, incluso, se invocaron límites relacionados con la soberanía, en discursos que resultaban bastante cuestionables.

De cualquier forma, seguramente fueron determinantes los informes que desde 1996 fueron emitidos por la Comisión Interamericana de Derechos Humanos, principalmente con relación a Aguas Blancas, al ejido Morelia y al caso del general Gallardo. Igualmente, la Comisión Interamericana emitió un informe analizando la situación general de los derechos humanos en México en la cual recomienda, entre otras cosas, que se considere la posibilidad de aceptar la competencia contenciosa de la CIDH. Otro evento importante fue la visita de la alta comisionada de las Naciones Unidas para los Derechos Humanos, Mary Robinson, en junio de 1998, quien, principalmente, se pronunció acerca de la situación de los derechos humanos en Chiapas. Sin embargo, seguramente también influyó la crítica que desde diversos sectores e instancias de la Unión Europea se emitieron hacia el gobierno mexicano, en un momento en el que México y la Unión Europea iniciaron la negociación de un acuerdo comercial.

A pesar de que, podemos suponer, que el gobierno mexicano aceptó la competencia de la CIDH por las presiones que antes mencionamos, el 
hecho es trascendente y abre un espacio más para lograr la mejor protección de los derechos humanos en nuestro país.

Al mismo tiempo, nos permite analizar la postura que tiene nuestro gobierno respecto a las instancias internacionales protectoras de los derechos humanos, la cual, por el contenido de la declaración que comentamos y por otros datos que mencionaremos, no parece ser muy diferente de la que mencionamos en el primer párrafo. El gobierno mexicano no aceptó ampliamente la competencia de la CIDH: por el contrario, formuló una reserva que limita la intervención de este órgano con relación a nuestro país.

La procedencia de esta, mal llamada, reserva, es un punto de análisis que denota la actitud de nuestro gobierno frente a las instancias internacionales y, también, demuestra aspectos especiales del trato a algunos extranjeros en nuestro país.

\section{ANTECEDENTES}

El 18 de diciembre de 1980 la Cámara de Senadores aprobó la participación de México en siete tratados protectores de los derechos humanos: ${ }^{1}$ el Pacto Internacional de Derechos Civiles y Políticos y el Pacto Internacional de Derechos Económicos, Sociales y Culturales, estos dos fueron adoptados en 1966; la Convención sobre los Derechos Políticos de la Mujer, de 1956; la Convención sobre la Eliminación de Todas las Formas de Discriminación contra la Mujer, de 1979; la Convención Americana sobre Derechos Humanos, de 1969; la Convención sobre Asilo Territorial, de 1954 y la Convención Interamericana sobre la Concesión de los Derechos Políticos a la Mujer, de 1948. En la exposición ${ }^{2}$ con la cual el presidente López Portillo presentó su propuesta al Senado, explica:

La adhesión formal a los preceptos consagrados por la comunidad internacional en estos instrumentos, y el compromiso de nuestro gobierno de aplicarlos en lo interno puesto que, al asumirlos, se convierten también en ley de la República conforme al artículo 133 constitucional, no pueden interpretarse como actos que lesionen en forma alguna la soberanía del estado

1 Los instrumentos respectivos fueron publicados en el Diario Oficial de la Federación el 9 de enero de 1981.

2 Exposición del Poder Ejecutivo de la Unión sobre los pactos y convenciones internacionales que promueven la protección de los derechos humanos, en Convenciones sobre derechos humanos, México, Secretaría de Relaciones Exteriores, 1981. 
mexicano, puesto que la adhesión y el compromiso son, en sí mismos, una forma de ejercer esa soberanía.

Obviamente, los gobiernos anteriores a éste no habían estado de acuerdo con el entonces presidente, en tanto que habiendo participado México en la negociación y adopción de los tratados a los que nos estamos refiriendo, no se había realizado su ratificación. En algunos casos, como denotan las fechas de adopción, habían transcurrido más de treinta años. Sin embargo, a pesar de la tardanza, es positiva la aceptación de las obligaciones señaladas en estos instrumentos.

\section{LA CONVENCIÓN AMERICANA SOBRE DERECHOS HUMANOS}

A nivel regional, los principales instrumentos de protección a los derechos son la Declaración Americana de los Derechos y Deberes del Hombre y la Convención Americana sobre Derechos Humanos, esta última se encuentra entre los tratados que antes mencionamos. El papel de México en la elaboración de la Declaración fue muy importante; en la Conferencia de Chapultepec en febrero de 1945 se proclamó la adhesión de las repúblicas americanas a los principios consagrados en el derecho internacional para la salvaguardia de los derechos esenciales del hombre, y México ${ }^{3}$ se pronunció en favor de un sistema de protección internacional de los mismos. La Conferencia en sus resoluciones IX y XL encomendó al Comité Interamericano la redacción de un proyecto de Declaración.

La idea original implicaba la aplicación de tal declaración mediante la creación de un sistema internacional de protección a los derechos humanos; sin embargo, tal postura se modificó al parecer por el riesgo de que, argumentando una violación a estos derechos, se daría la posibilidad de intervenir política o judicialmente en los asuntos internos; el temor no era en vano, los países americanos habían sufrido la intervención, ilegítima, de varias potencias, y Estados Unidos controlaba de manera importante los intentos de organización regional, esto los hacía pensar en una influencia legitimada por el derecho internacional.

México, en un primer momento, había propuesto la protección internacional porque suponía que así se eliminaría

3 Más información respecto al papel de México en Fernández del Castillo, G., "La Declaración Americana de los Derechos y Deberes del Hombre", Revista de Investigaciones Jurídicas, México, año 8, núm. 8, tomo I, 1984. 
el uso indebido de la protección diplomática de los ciudadanos en el exterior, cuyo ejercicio ha determinado más de una vez la violación del principio de no intervención, y también el de igualdad entre nacionales y extranjeros, en cuanto a los derechos esenciales del hombre, pero la delegación mexicana apreció que la protección internacional, ya fuera jurídica o ya fuera judicial, no eliminaría los inconvenientes de la protección diplomática, sino que los agravaría, toda vez que cualquier violación sujetaría a México, al igual que a los demás países de América, más tarde o más temprano, a la intervención política o judicial en sus asuntos internos, realizada por un organismo que por su carácter internacional tendría más fuerza aún que la del Estado que reclamara mediante la protección diplomática. ${ }^{4}$

Por fin se llegó a la conclusión de que debía adoptarse una declaración y no la convención que se pensó primeramente, y que la implementación de la protección de los derechos humanos no debía realizarse en ese momento dejándose como un acto a futuro. Esta actitud cambia, tal vez por la proliferación de gobiernos autoritarios en la región y el consecuente peligro que éstos representaban para la población; en la V Reunión de Consulta de Ministros de Relaciones Exteriores ${ }^{5}$ se emitieron varias resoluciones con relación a los derechos humanos destacando, entre ellas, la VII, en la cual se decide la preparación de un proyecto de convención sobre derechos humanos y la creación de la Comisión Interamericana de Derechos Humanos.

La Convención Americana sobre Derechos Humanos fue adoptada el 22 de noviembre de 1969 por la Conferencia Especializada Interamericana sobre Derechos Humanos celebrada en San José de Costa Rica; previamente, el 25 de mayo de 1960, fue aprobado el Estatuto de la Comisión por el Consejo de la Organización de Estados Americanos. La Comisión será un órgano independiente hasta que el Protocolo de Buenos Aires de 1967 reforma la Carta de la OEA y la Comisión adquiere la jerarquía de órgano principal de la Organización. Al adoptarse la Convención Americana se incluye a la Comisión en ella, como un mecanismo de garantía, junto con la Corte Interamericana de Derechos Humanos.

5 Quinta Reunión de Consulta, Santiago de Chile, del 12 al 18 de agosto de 1959, Acta Final OEA, Documento OEA/Serie C/II 5, pp. 10-12. 


\section{LA COMISIÓN Y LA CORTE INTERAMERICANAS DE DERECHOS HUMANOS}

Estas dos instituciones son las encargadas de proteger los derechos humanos en América; sus funciones específicas y sus facultades son diferentes, pero se reconoce su labor a lo largo del tiempo, aunque existen limitaciones estructurales y políticas para la misma.

La Comisión inició sus funciones en 1960. Éstas van desde la promoción de los derechos humanos en el continente hasta la de recibir reclamaciones (peticiones, según la Convención) y realizar visitas in loco.

La evolución que ha tenido la Comisión ha provocado lo que se conoce como una doble base legal para determinar la competencia de la Comisión con relación a los Estados que son partes de la Convención y los que no lo son. Estos últimos se regulan por la Declaración Americana de Derechos y Deberes del Hombre de 1949 y por el Estatuto de la Comisión aprobado en 1960 con las modificaciones hechas por la Segunda Conferencia Interamericana; mientras que a los Estados partes de la Convención los regula ésta y el nuevo Estatuto de la Comisión adoptado por la Asamblea General en su Noveno Periodo de Sesiones, en la Paz, Bolivia (31 de octubre de 1979).

De acuerdo con el artículo 41 de la Convención Americana, función principal de la Comisión es promover la observancia y la defensa de los derechos humanos, y en el ejercicio de su mandato tiene las siguientes funciones y atribuciones:

$a$. estimular la conciencia de los derechos humanos en los pueblos de América; $b$. formular recomendaciones, cuando lo estime conveniente, a los gobiernos de los Estados miembros para que adopten medidas progresivas en favor de los derechos humanos dentro del marco de sus leyes internas y sus preceptos constitucionales, al igual que disposiciones apropiadas para fomentar el debido respeto a esos derechos; $c$. preparar los estudios e informes que considere convenientes para el desempeño de sus funciones; $d$. solicitar de los gobiernos de los Estados miembros que le proporcionen informes sobre las medidas que adopten en materia de derechos humanos; $e$. atender las consultas que, por medio de la Secretaría General de la Organización de los Estados Americanos, le formulen los Estados miembros en cuestiones relacionadas con los derechos humanos y, dentro de sus posibilidades, les prestará el asesoramiento que éstos le soliciten; $f$. actuar respecto de las peticiones y otras comunicaciones en ejercicio de su autoridad de 
conformidad con lo dispuesto en los artículos 44 a 51 de esta Convención, y $g$. rendir un informe anual a la Asamblea General de la Organización de los Estados Americanos (artículo 41 de la Convención Americana).

Para el tema que estamos analizando, la función que nos interesa es la que tiene que ver con las peticiones que se le formulan a la Comisión. Realmente de lo que estamos hablando es de las denuncias o quejas que se le presentan a este órgano por la supuesta violación a derechos humanos. El artículo 26 del reglamento de la Comisión señala quiénes son los sujetos legitimados para acudir ante la Comisión para presentar una petición:

1. Cualquier persona o grupo de personas, o entidad no gubernamental legalmente reconocida en uno o más Estados miembros de la Organización puede presentar a la Comisión peticiones de conformidad con el presente reglamento, en su propio nombre o en el de terceras personas, referentes a presuntas violaciones de un derecho humano reconocido, según el caso, en la Convención Americana sobre Derechos Humanos o en la Declaración Americana de los Derechos y Deberes del Hombre.

También, la denuncia la puede presentar un Estado parte contra otro Estado parte de la Convención, pero ambos deben reconocer la competencia de la Comisión. La declaración de aceptación de competencia puede hacerse al ratificar la Convención, al adherirse a ella, o en cualquier momento posterior. Tal declaración puede hacerse para regir por tiempo indefinido, y por un periodo determinado o para casos específicos.

Hemos señalado estos aspectos de la función de la Comisión en tanto que, para que la Corte conozca de un asunto, es necesario que se haya agotado el procedimiento previsto en los artículos 48 a 50 de la Convención; esto significa que debió cubrirse el procedimiento ante la Comisión, teniendo como colofón que la Comisión elaboró un informe confidencial y se lo comunicó al Estado involucrado.

La Corte Interamericana de Derechos Humanos no está considerada en la Carta de la OEA como un órgano de la organización. Esta situación ha sido criticada por varios internacionalistas, ${ }^{6}$ en tanto que no existen razones para que no se le incluya como órgano de la misma manera que se considera a la Comisión. Se supone que la principal objeción a la inclusión de la Corte como órgano de la OEA, seguramente, provendría de

6 Al respecto puede verse la propuesta que elabora Gros Espiell, Héctor, en: Estudios sobre derechos humanos, Madrid, Civitas, 1998, p. 198. 
los Estados que no son parte en la Convención Americana, ya que considerarían esto como una vinculación obligatoria a la Corte; sin embargo, esto no es así en tanto que seguiría funcionando la aceptación voluntaria de la competencia de la Corte.

El objetivo de la Corte es la aplicación e interpretación de la Convención Americana sobre Derechos Humanos; para ello, ejerce dos funciones: jurisdiccional y consultiva. La función consultiva puede ser accionada por los Estados miembros de la OEA, sean o no partes de la Convención, por los órganos permanentes de la OEA y por la Comisión Interamericana. En cuanto al alcance de esta función, la Corte ha dicho que ella puede opinar con relación a "toda disposición concerniente a la protección de los derechos humanos, de cualquier tratado internacional, con independencia de que sea bilateral o multilateral, de cual sea su objeto principal o de que sean o puedan ser partes en él Estados ajenos al sistema interamericano". ${ }^{7}$ Los efectos jurídicos de las opiniones consultivas son limitados si los comparamos con las sentencias. La misma Corte ha aceptado que una opinión consultiva no obliga a los Estados. En este sentido, la función consultiva "ofrece un método judicial alterno de carácter consultivo, destinado a ayudar a los Estados y órganos a cumplir y a aplicar tratados en materia de derechos humanos sin someterlos al formalismo y al sistema de sanciones del proceso contencioso" ${ }^{8}$

\section{LA COMPETENCIA CONTENCIOSA DE LA CORTE INTERAMERICANA}

El procedimiento para la función contenciosa de la Corte se encuentra más detallado que el de la consultiva. Seguramente esto es así en aras de una mayor claridad para la función más importante de este órgano. Si bien la función consultiva es, ya de suyo, relevante, no podemos negar que la función contenciosa es, por sus características, la más importante, ya que posibilita a la Corte para proteger de una manera más eficaz los derechos humanos y, en último caso, permite reivindicar y/o indemnizar a quien haya sido afectado por la violación de sus derechos. Sin embargo, esos mismos fines que persigue esta función provocan cierta resistencia a

7 CIDH, "Otros tratados" objeto de la función consultiva de la Corte (artículo 64 de la Convención Americana sobre Derechos Humanos), Opinión Consultiva OC-I/82 del 24 de septiembre de 1982, Serie A, núm. 1, par. 52.

8 CIDH, Restricciones a la pena de muerte, Opinión Consultiva OC-3/83 del 8 de septiembre de 1983, Serie A, núm. 3, par. 43. 
su actuación por parte de los Estados; por eso, su procedimiento debe ser claro, tratando de evitar, al máximo, las lagunas procesales que pudieran entorpecer su función.

A la Corte le puede ser presentado el caso, solamente, por los Estados partes y por la Comisión. Esto significa que si el denunciante ante la Comisión fue un particular, no podrá llevarlo ante la Corte, en cuyo caso la misma Comisión podría hacerlo. Sin duda, esta limitación se debe a los resabios de la consideración tradicional de los sujetos del derecho internacional, que al parecer ha cambiado, lo cual no evita que algunos de sus efectos pervivan. Afortunadamente, la tendencia es otorgar facultades de acción para los individuos ante los tribunales internacionales. ${ }^{9}$

Para que la Corte conozca de una asunto, el Estado parte involucrado debe haber aceptado la competencia de la Corte, como lo señala el artículo 62 de la Convención, mediante una declaración o una convención especial:

1. Todo Estado Parte puede, en el momento del depósito de su instrumento de ratificación o adhesión de esta Convención, o en cualquier momento posterior, declarar que reconoce como obligatoria de pleno derecho y sin convención especial, la competencia de la Corte sobre todos los casos relativos a la interpretación o aplicación de esta Convención.

2. La declaración puede ser hecha incondicionalmente, o bajo condición de reciprocidad, por un plazo determinado o para casos específicos. Deberá ser presentada al Secretario General de la Organización, quien transmitirá copias de la misma a los otros Estados miembros de la Organización y al Secretario de la Corte.

3. La Corte tiene competencia para conocer de cualquier caso relativo a la interpretación y aplicación de las disposiciones de esta Convención que le sea sometido, siempre que los Estados partes en el caso hayan reconocido o reconozcan dicha competencia, ora por declaración especial, como se indica en los incisos anteriores, ora por convención especial.

Como vemos, si el Estado no hace la declaración de aceptación, el asunto no puede ser conocido por la Corte, en función contenciosa. En este caso queda la posibilidad de que la Corte intervenga en función consultiva, pero su opinión tiene efectos diferentes a los de una sentencia.

9 En el Protocolo número 11 de la Convención Europea de Derechos Humanos, que fue adoptado en 1994, se reconoce la facultad de acceso directo a la Corte Europea, a los individuos. 


\section{CONTENIDO Y ALCANCE DE LA DECLARACIÓN HECHA POR EL GOBIERNO MEXICANO}

Como lo señalamos al inicio de este trabajo, el gobierno de México depositó su instrumento de adhesión a la Convención Americana en 1981, el 24 de marzo. En el mismo acto México presentó las siguientes declaraciones interpretativas y reserva. ${ }^{10}$

\section{DECLARACIONES INTERPRETATIVAS}

Con respecto al párrafo 1 del artículo 4o. (el gobierno mexicano) considera que la expresión "en general", usada en el citado párrafo, no constituye obligación de adoptar o mantener en vigor legislación que proteja la vida "a partir del momento de la concepción", ya que esta materia pertenece al dominio reservado de los Estados.

Por otra parte, en concepto del gobierno de México, la limitación que establece la Constitución Política de los Estados Unidos Mexicanos, en el sentido de que todo acto público de culto religioso deberá celebrarse precisamente dentro de los templos, es de las comprendidas en el párrafo 3 del artículo 12.

\section{RESERVA}

El gobierno de México hace reserva expresa en cuanto al párrafo 2 del artículo 23 ya que la Constitución Política de los Estados Unidos Mexicanos, en su artículo 130, dispone que los ministros de los cultos no tendrán voto activo, ni pasivo, ni derechos para asociarse con fines políticos.

En ese entonces el Presidente mexicano no consideró prudente aceptar la competencia contenciosa de la Corte ya que, según él, "estaría fuera de lugar por ahora, toda vez que la legislación nacional prevé los recursos necesarios para corregir cualquier falla en la estructura de preservación de las garantías individuales y sociales en el país". ${ }^{11}$

Finalmente, el gobierno mexicano acepta, después de la presión internacional desatada por la publicidad de graves violaciones a los derechos humanos en nuestro territorio, la competencia de la Corte Interamericana.

10 Convenciones..., op.cit., nota 1, p. 105.

11 Ibidem, pp. 22-23. 
La Declaración para el Reconocimiento de la Competencia Contenciosa de Corte Interamericana de Derechos Humanos tiene el siguiente texto:

1. Los Estados Unidos Mexicanos reconocen como obligatoria de pleno derecho, la competencia contenciosa de la Corte Interamericana de Derechos Humanos, sobre los casos relativos a la interpretación o aplicación de la Convención Americana sobre Derechos Humanos, de conformidad con el artículo 62.1 de la misma, a excepción de los casos derivados de la aplicación del artículo 33 de la Constitución Política de los Estados Unidos Mexicanos.

1. La aceptación de la competencia contenciosa de la Corte Interamericana de Derechos Humanos solamente será aplicable a los hechos o a los actos jurídicos posteriores a la fecha del depósito de esta declaración, por lo que no tendrá efectos retroactivos.

2. La aceptación de la competencia contenciosa de la Corte Interamericana de Derechos Humanos se hace con carácter general y continuará en vigor hasta un año después de la fecha en que los Estados Unidos Mexicanos notifiquen que la han denunciado.

Los dos últimos párrafos de la declaración no ameritan comentarios, incluso resultan obsoletos, ya que sólo repiten aspectos que la misma Convención señala.

Aun cuando es bienvenido el reconocimiento que el gobierno mexicano ha otorgado, nuevamente estamos en presencia de un acto jurídicamente controversial que nos confirma lo que Rodríguez y Rodríguez antes ha señalado, "la participación de nuestro país en el proceso de reconocimiento y protección internacional de los derechos y libertades fundamentales de la persona humana ha sido, en cuanto a su reconocimiento, tardía, $\mathrm{y}$, en cuanto a la protección, incompleta". ${ }^{12}$

Tácitamente, México ha formulado reserva a la jurisdicción contenciosa de la Corte, al excluir lo relativo a la aplicación del artículo 33 de la Constitución. Esto no es acorde con el artículo 19 de la Convención sobre Derecho de los Tratados, que señala que la reserva se podrá formular en el momento de firmar, ratificar, aceptar, aprobar o adherirse al tratado. En su caso, el gobierno mexicano no formuló reservas sobre el artículo 33 constitucional en el momento de la adhesión, lo cual le permitiría derivar

12 Rodríguez y Rodríguez, Jesús (compilador), Instrumentos internacionales sobre derechos humanos, México, Comisión Nacional de Derechos Humanos, 1994, p. 10. 
sus efectos, también, a la competencia contenciosa de la Corte, aceptada posteriormente.

Esta anomalía se presenta, precisamente, en un momento en el que dicho artículo está siendo muy cuestionado por su contenido violatorio de varios derechos humanos consignados en diversos instrumentos internacionales, entre ellos, la Convención Americana de Derechos Humanos. En especial, este artículo y las disposiciones respectivas de la Ley General de Población han sido utilizados para expulsar del país a extranjeros que realizaban labores de observación de los derechos humanos, principalmente relacionados con el conflicto zapatista. Por su contenido y su aplicación este artículo ha sido criticado por los defensores de los derechos humanos, "este precepto constitucional es un generador de violaciones de los derechos humanos, básicamente en dos sentidos: el primero, a través del agravio directo que se comete al observador internacional, y el segundo, como un impedimento para que se conozca el estado de los derechos humanos a través de la observación internacional". ${ }^{13}$

En términos estrictamente jurídicos, el maestro Santiago Corcuera considera que la reserva es nula, por dos razones:

primera: si México no hizo una reserva en el momento de adherirse a la parte sustantiva (la convención) no puede hacerla después en la parte adjetiva (la jurisdicción de la Corte). Segunda: La Corte Interamericana seguiría los pasos de su similar europea, la que ya abordó un caso similar al que puede presentarse en México. Fue el caso Loizidou. En él, la Corte Europea desconoció la reserva que había presentado Turquía para el caso de afectación de un extranjero en el norte de Chipre. ${ }^{14}$

Aun cuando no estemos de acuerdo con la reserva formulada por México al aceptar la competencia de la Corte, debemos reconocer que la redacción del artículo permite una interpretación acorde con la intención del gobierno mexicano. En el primer párrafo del artículo 62 se determina la facultad del Estado de reconocer "como obligatoria de pleno derecho y sin convención especial, la competencia de la Corte sobre todos los casos relativos a la interpretación o aplicación de esta Convención", lo cual nos lleva a señalar que no admite la formulación de límites en cuanto a la materia de conocimiento por la Corte, y de esta manera no sería aceptable

13 Citado por Campa, Homero, "Cientos de extranjeros expulsados desde el estallido zapatista”, Proceso/Infolatina, México, 16 de enero del 2000.

14 Idem. 
la reserva basada en el artículo 33 constitucional. Sin embargo, aunque nos parece lamentable, el párrafo segundo permite que la declaración de reconocimiento se otorgue "por un plazo determinado o para casos específicos"; esta frase presenta una posibilidad radical en la cual el Estado puede decidir sobre qué asuntos puede actuar la Corte, con relación a él, y por ello, en sentido contrario se otorga la facultad de señalar los asuntos que no se incluyen. Obviamente, no es esta última interpretación la que nos parece más adecuada para la protección y vigencia de los derechos humanos; por el contrario, es lamentable que el gobierno mexicano mantenga su postura de rechazo a la acción de las instancias protectoras de los derechos humanos, y sobre todo que lo haga con base en una norma interna que resulta absolutamente violatoria de derechos humanos fundamentales.

La posibilidad de que la Corte decidiera, en el caso concreto, que tiene competencia de conocer de un asunto de aplicación del artículo 33 de la Constitución mexicana, no será atacando la validez de la reserva formulada con la declaración, sino, como en el caso que señala Corcuera, la Corte podría no respetar la reserva por la índole del derecho protegido. De cualquier forma, esto provocaría que, nuevamente, nuestro gobierno se enfrentaría al análisis internacional, cuando esto puede ser resuelto con base en una actitud convencida de acatamiento de los tratados internacionales y su incorporación a nuestra legislación; en este caso modificando el texto del artículo 33 constitucional.

\section{BIBLIOGRAFÍA}

CAMPA, Homero, "Cientos de extranjeros expulsados desde el estallido zapatista”, Proceso/Infolatina, México, 16 de enero del 2000.

CIDH, "Otros tratados" objeto de la función consultiva de la Corte (art. 64 de la Convención Americana sobre Derechos Humanos), Opinión Consultiva OC-I/82 del 24 de septiembre de 1982, Serie A, núm. 1, par. 52.

— - Restricciones a la pena de muerte, Opinión Consultiva OC-3/83 del 8 de septiembre de 1983, Serie A, núm. 3, par. 43.

Diario Oficial de la Federación de 9 de enero de 1981.

"Exposición del Poder Ejecutivo de la Unión sobre los Pactos y Convenciones Internacionales que promueven la Protección de los Derechos 
Humanos", Convenciones sobre Derechos Humanos, México, Secretaría de Relaciones Exteriores, 1981.

FERNÁNDEZ DEL CASTILlO, G., "La Declaración Americana de los Derechos y Deberes del Hombre", Revista de Investigaciones Jurídicas, México, año 8, núm. 8, t. I, 1984.

GROS EsPIELL, Héctor, Estudios sobre derechos humanos, Madrid, Civitas, 1998.

Protocolo Núm. 11 de la Convención Europea de Derechos Humanos, que fue adoptado en 1994.

Quinta Reunión de Consulta, Santiago de Chile, del 12 al 18 de agosto de 1959, Acta Final OEA, Documento OEA/Serie C/II 5.

RODRÍGUEZ Y RODRÍGUEZ, Jesús (compilador), Instrumentos internacionales sobre derechos humanos, México, Comisión Nacional de Derechos Humanos, 1994. 